\title{
An Add Environmental Dimension Using BIM-LCA integration Technology
}

\author{
Huang Yangyang1,a ${ }^{1,}$ Zhiqi Gong ${ }^{2, b *}$ \\ ${ }^{1}$ Civil Engineeringt Department, Qing Hai University Xining, China \\ ${ }^{2}$ QingHai university Xining, China
}

\begin{abstract}
In addition to consuming a large amount of energy resources, buildings inevitably destroy the ecological environment in the process of construction. Its main performance in water pollution, air pollution, construction waste and so on. Life Cycle Assessment (LCA) is an international standard method which systematically and quantitatively describes various resources, energy consumption and environmental emissions in product Life Cycle and evaluates their environmental impacts. The integration of building information model and LCA method will avoid repeated modeling and simplify data collection, and provide a certain technical framework for the development of BIM6D. In this paper, the BIM-LCA integration framework and the BIM6D model are established, and the environmental impact of a building in the quantitative analysis is used to guide the development of the BIM6D.
\end{abstract}

\section{Introduction}

The construction industry is responsible for various negative impacts on the environment, consuming about $40 \%$ of global energy and releasing $25 \%$ of $\mathrm{CO} 2$ emissions[1][2]. As population growth continues, the demand for buildings is increasing. Since 1970, energyrelated greenhouse gas (GHG) emissions from the operation of buildings have more than doubled, accounting for $19 \%$ of the total emissions in 2010 [3].

In the past, life cycle assessment (LCA) has been widely used to measure and evaluate the environmental impact of buildings throughout their life cycle. By defining the analysis scope of the building in its whole life cycle, the potential energy consumption, carbon emission and environmental impact can be fully understood, which can provide relevant guidance for the researchers to carry out the building environmental assessment. However, when the LCA method is used, the data base is large as the researchers need to calculate the whole life cycle environment of the building according to the complicated process from raw material mining to the demolition, treatment and recovery of the building waste. And that this approach is an afterthought as if rather than providing feedback to improve the design of the building.

To facilitate green building designs, Building Information Modelling(BIM) emerged as a technology and process allowing 3D modelling and information management throughout the life cycle of buildings[4]. Therefore, when applying BIM to LCA research, it will simplify the data collection of buildings in the life cycle assessment process. In addition, BIM can take advantage of its own advantages to produce integrated design, support Information Management and collaboration among stakeholders throughout the life cycle of the project.

So far, researchers have found the importance of BIM in promoting environmental management throughout the life cycle of buildings. Existing research has focused on combining BIM with "green building" or "building sustainability" and giving a new definition to "Green BIM"_ _ "a model-based process of generating and managing coordinated and consistent building data that facilitates the accomplishment of established sustainability goals[5]. However, these studies only use BIM as a means of semi-automated LCA estimation using its automatically generated material quantities take off (MQT). The aim of this paper is to put forward a framework, which integrates environmental management into BIM5D to form BIM6D, in order to realize the progress, cost and environmental management of buildings in construction, operation and obsolescence.

\section{Theoretical analysis of BIM6D based on BIM-LCA}

\subsection{BIM-LCA evaluation process}

The BIM-LCA evaluation process is shown in figure 1. By simplifying the process of building life cycle, the information extraction function of BIM 3D model is used to collect basic data. Building 3D model is constructed, and BIM software is used to simulate the whole life cycle of the building in the design phase, so as to quantify the resource consumption, energy consumption and material consumption. According to the output of BIM to complete

b* Corresponding author's e-mail address: gzhq2007@foxmail.com 
the LCI stage of LCA evaluation method, the LCI data are classified, characterized and standardized.

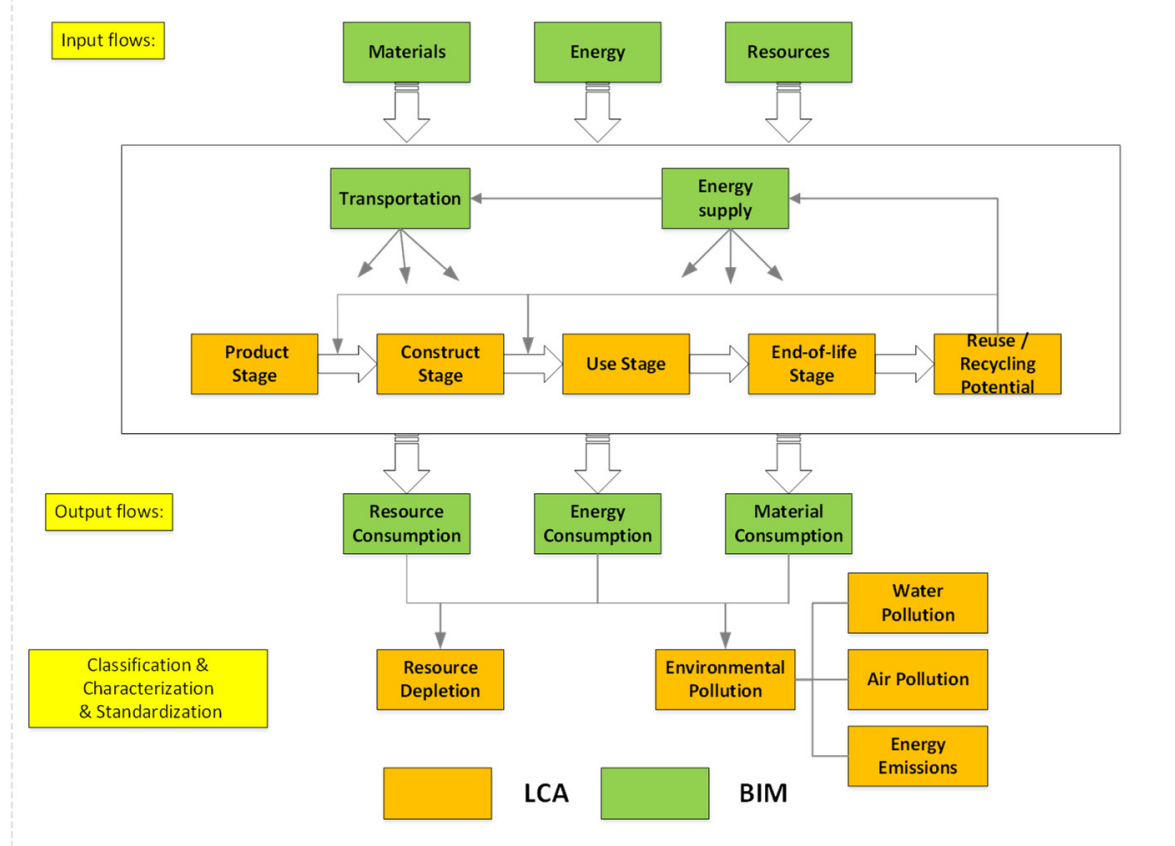

Figure 1. BIM-LCA evaluation process

A more advanced approach to BIM-LCA Integration Research and analysis is to model Revit software based on TALLY plug-ins[6]. Tally is a Revit based Life Cycle Assessment Plugin released by Autodesk in 2014. The life cycle inventory database is based on North American evaluation criteria. Unlike Gabi and other life cycle assessment plug-ins, Tally database is dedicated to the construction industry, and the data set is representative in accuracy and breadth. Tally results can be used for a comprehensive analysis of a building or a comparative analysis of a design. It can explain the range of different materials defined in BIM models, as well as materials that are not explicitly modeled, as shown in figure 2 .

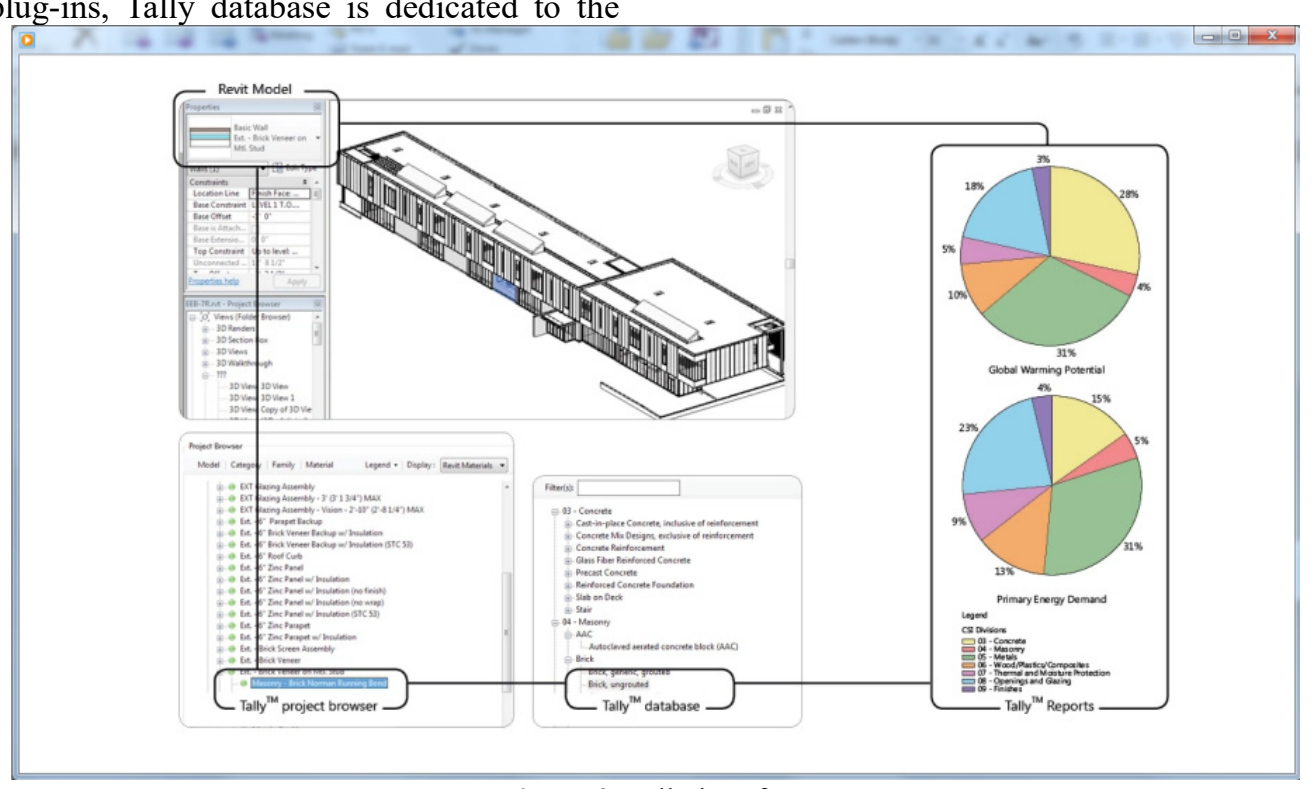

Figure 2. Tally interface

Source: https://choosetally.com/\#

\subsection{Theoretical analysis of BIM 6D}

BIM 6D is a three-dimensional model that takes into account the time dimension, the capital dimension and the environmental dimension, as shown in figure 3. BIM6D is not only a model that reflects the life cycle of a building, but also a management process that runs through the design, construction and operation of a building. By integrating the LCA method into the BIM5D platform, on the one hand, the environmental information can be obtained dynamically, on the other hand, the dialectical relationship between cost and environment can be concerned in real time, and the project management can be improved. The BIM-LCA integration provides the theoretical and practical basis for BIM 6D, and the next step is for the researchers to link the LCA database to BIM 5D using a computer software development program. At present, the development of Tally plug-in advances the research of BIM-LCA integration. 


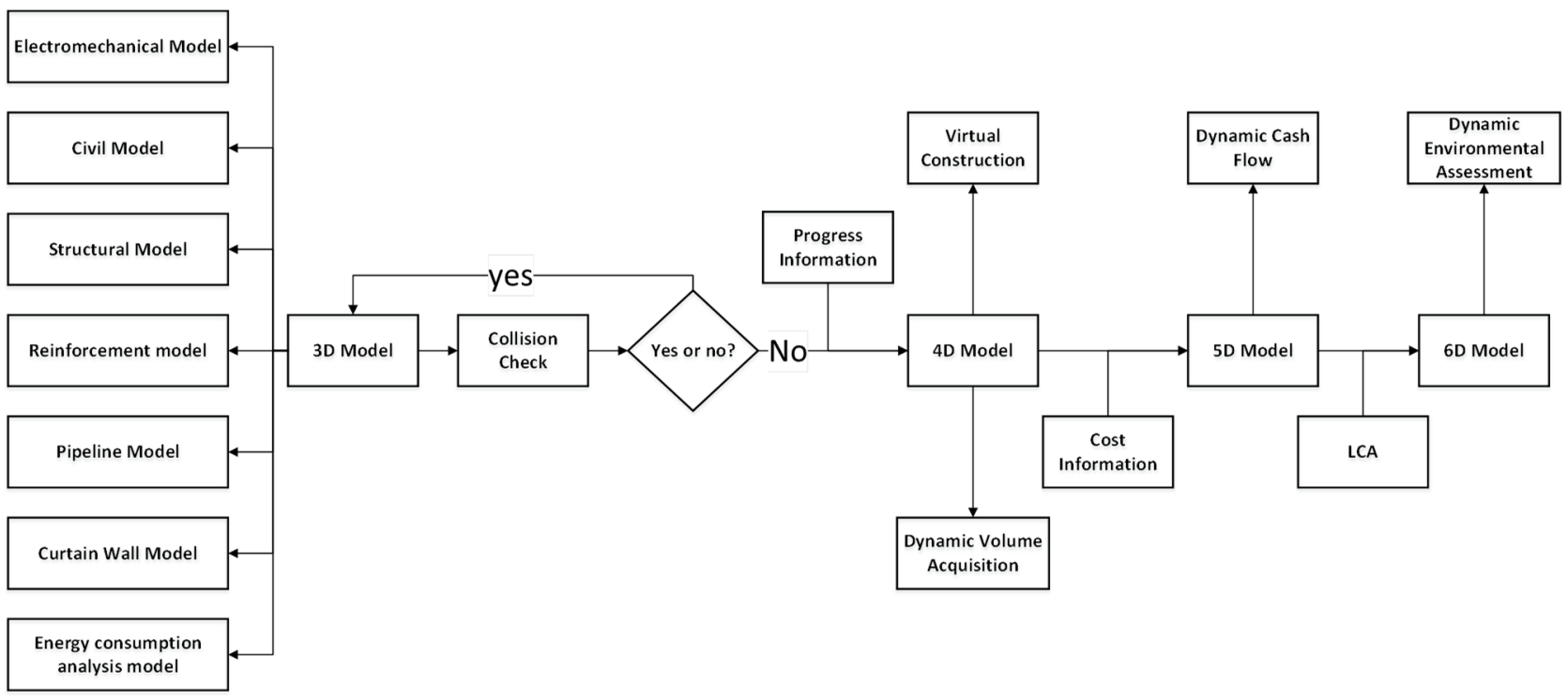

Figure 3. Flow chart of BIM6D model construction

\section{Case Analysis}

\subsection{Engineering overview}

The project is a three-storey mixed-structure Villa located in Xining with an independent foundation with a total floor area of $450 \mathrm{~m}^{2}$. The ground floor is $3.6 \mathrm{~m}$, the height of two or three stories is $3.3 \mathrm{~m}$, indoor and outdoor height difference $0.2 \mathrm{~m}$. The design life is 60 years, the roofing waterproof grade is II, the durable life is 15 years, the building fire grade is III. The annual average electricity consumption per unit area is $23 \mathrm{kw} \mathrm{h} / \mathrm{m}^{2}$. A, the annual average energy consumption per unit area is $293.4 \mathrm{MJ} / \mathrm{m}$ 2. $a^{-1}$.

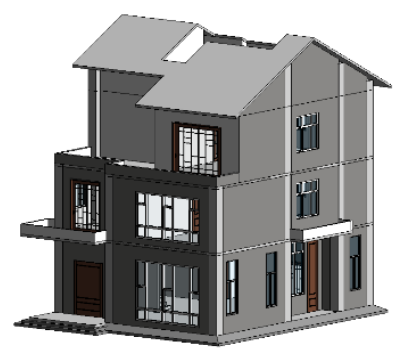

Figure 4. R evit3D model

\subsection{Calculation results based on BIM-LCA model}

With the help of Tally plug-in, 8 different characteristic indexes are calculated. Figure 5A shows the environmental impact of building materials and energy at different stages of the villa's life cycle. The results show that the environmental impact of the operational phase is much higher than that of the other phases, accounting for about $86 \%$ of the GWP. At the same time, the production of building materials on the environmental impact can not be underestimated. Secondly, because the amount of concrete and solid brick is more in the proportion of each environmental index, this result can help to compare the green performance of building materials in the early stage of design, and should be used in the design stage, pay attention to the impact of different building materials on the environment, on the premise of not affecting the safety of the design scheme, priority is given to the selection of environmental protection materials that have less impact on the environment. Designers should also take full account of the building's thermal insulation and daylighting to reduce the use of energy consumption during the operation phase.

In the physico-chemical environmental impact analysis of the new building components, because the main material of the wall is brick structure, and the main structural material of the floor is reinforced concrete, the proportion of which is higher, and the proportion of the two in each environmental index is larger. The door and window components are processed in multiple processes, so the components have higher energy content and more obvious impact on the environment, as shown in figure 5B. 

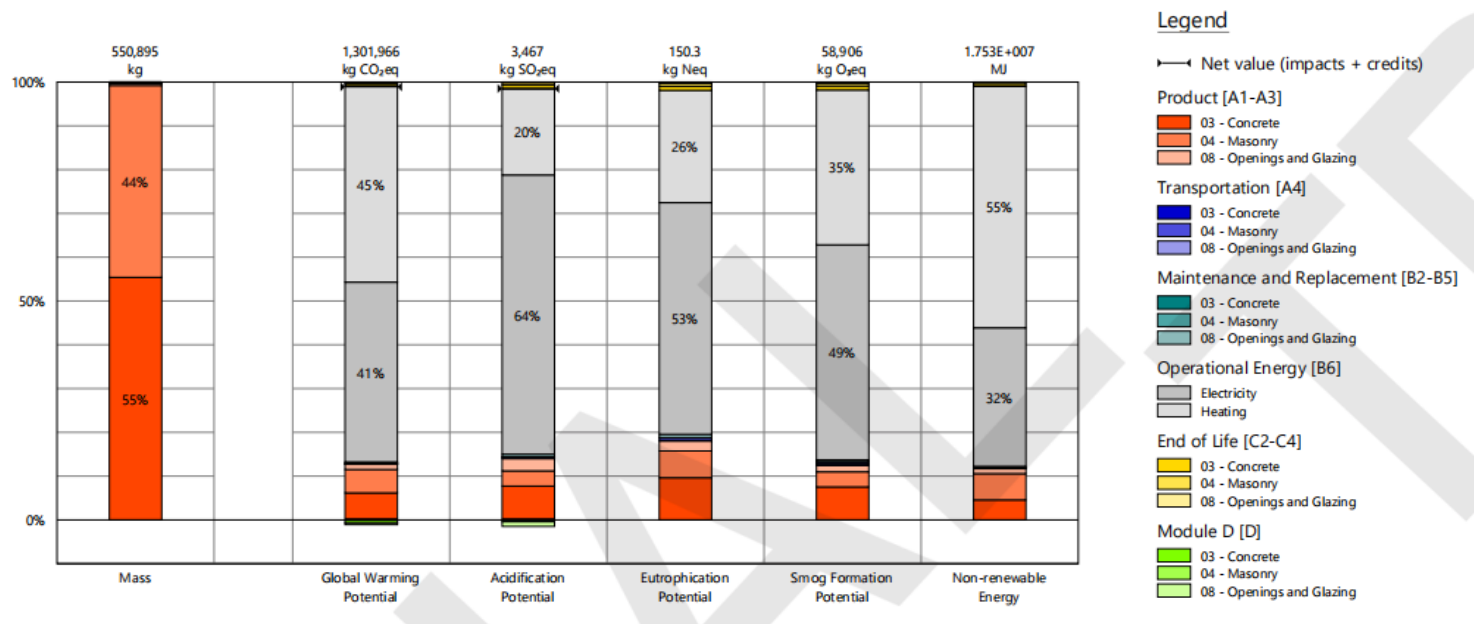

A. Environmental impact of different building materials at different stages

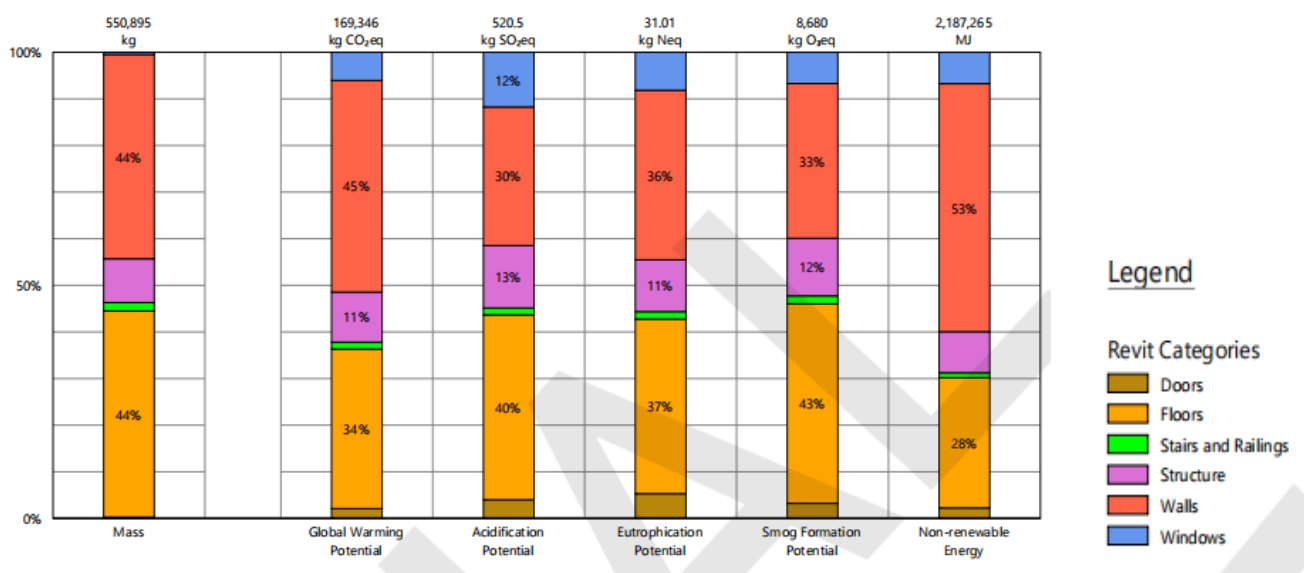

B. Environmental impact of different building materials at different stages

Figure 5. Calculation results based on BIM-LCA model

\section{Conclusion}

The research on the integration of BIM-LCA will greatly promote the construction of the BIM6D model. The current research on BIM-LCA is still in its infancy and the related software development is immature. The TALLY plug-in used in this modeling analysis is currently the only LCA database integrated into the BIM software. However, because the plug-in was developed by architects, it mainly analyzes the environmental properties of building materials, which still has some gaps compared with professional LCA tools such as Gabi and Simpro. In addition, the LCA database used by TALLY plug-in comes from abroad, so there is a gap in calculating the domestic building environmental impact results. Future research will focus on developing china-based BIM-LCA integration tools and improving their applications to facilitate the construction of the BIM6D platform.

\section{Acknowledgement}

Qinghai Applied Basic Research Project (2018-ZJ-734), Qinghai Province Science and Technology Foundation
Platform Project (2018-ZJ-T01)

Qinghai Provincial Key Laboratory of Energy-saving Building Materials and Engineering Safety

\section{References}

1. Carvalho J P, Braganca L, Mateus R. Optimising building sustainability assessment using BIM[J]. Automation in Construction, 2019, 102(JUN.):170182.

2. Metz, B., Davidson, O.R., Bosch, P.R., Dave, R., and Meyer, L.A. (2007). Contribution of working group III to the fourth assessment report of the intergovernmental panel on climate change.

3. IPCC, 2014. Climate Change 2014: Mitigation of Climate Change. Summary for Policymakers and Technical Summary.

4. Lu, Y., Wu, Z., Chang, R., \& Li, Y. (2017). Building Information Modeling (BIM) for green buildings: A critical review and future directions. Automation in Construction, 83, 134-148.

5. Wong, J. K. W., \& Zhou, J. (2015). Enhancing 
environmental sustainability over building life cycles through green BIM: A review. Automation in Construction, 57, 156-165.

6. Shen Lin. Environmental Impact Assessment Study on the whole life cycle of construction project based on BIM technology. 2015. 